\title{
OS HONORÁVEIS MESTRES DE ARTES MARCIAIS ORIENTAIS: CARREIRA EMPREENDEDORA
}

\section{THE HONORABLE MASTERS OF ORIENTAL MARTIAL ARTS: ENTREPRENEURIAL CAREER}

\author{
SIDNEY ROBERTO CABRAL \\ PPG em Administração e Controladoria - Universidade Federal do Ceará (UFC) \\ Mestre em Administração e Controladoria - Universidade Federal do Ceará (UFC) \\ Orcid: http://orcid.org/0000-0002-3881-6449 / E-mail: prof.sidney77@gmail.com \\ Universidade Federal do Ceará, Programa de Pós-graduação em Administração e Controladoria, \\ Avenida da Universidade, 2431 - Benfica, Fortaleza - CE, CEP: 60020-180 \\ SERAFIM FIRMO DE SOUZA FERRAZ \\ Professor do PPG em Administração e Controladoria - Universidade Federal do Ceará (UFC) \\ Doutor em Administração de Empresas - Fundação Getúlio Vargas (EAESP-FGV) \\ Orcid: http://orcid.org/0000-0002-7849-4632 / E-mail: sfsf@uol.com.br

\section{LUIS EDUARDO BRANDÃO PAIVA} \\ PPG em Administração e Controladoria - Universidade Federal do Ceará (UFC) \\ Doutor em Administração e Controladoria - Universidade Federal do Ceará (UFC) \\ Orcid: http://orcid.org/0000-0002-5036-6823 / E-mail: edubrandas@gmail.com
}

Submissão: 23/02/2021. Revisão: 02/06/2021; 30/11/2021. Aceite: 19/01/2022. Publicação: 01/02/2022. DOI: http://dx.doi.org/10.22277/rgo.v15i1.6124

\section{RESUMO}

Objetivo: Investigar o desenvolvimento da carreira dos honoráveis mestres das artes marciais orientais.

Método / abordagem: O estudo é qualitativo, considerando os estágios e ciclos da carreira empreendedora. Teve como universo 6 honoráveis mestres de artes marciais orientais. Utilizou-se as entrevistas semiestruturadas, realizadas entre novembro de 2014 e setembro de 2015, com um conjunto de técnicas inerentes à análise de conteúdo, seguindo as etapas: (i) pré-análise, (ii) exploração do material e (iii) tratamento dos resultados, inferência e interpretação.

Principais resultados: A carreira dos sujeitos resultou em uma forma singular, multicanal e multicíclica, em modelo de coexistência da carreira de mestre e da carreira empreendedora. $\mathrm{Na}$ maestria, o indivíduo permanece em crescimento durante toda a vida, sem saída ou aposentadoria da organização. No viés empreendedor, os empreendimentos se somam com o intuito de agregar valor e patrimônio.

Contribuições metodológicas / sociais / gerenciais: O estudo contribui para o campo do conhecimento da carreira empreendedora dos honoráveis mestres de artes marciais. Esperase que esse passo se some ao bojo das pesquisas e desperte a oportunidade em um novo filão por parte de instituições, pesquisadores e entes públicos, para as possibilidades que esse ramo cultural pode oferecer, tanto nos aspectos filosóficos como nos aspectos econômicos.

Originalidade / relevância: Os honoráveis mestres, enquanto empreendedores, tendem a conduzir carreiras e vidas em consonância com empreendimentos e mestria, e isto é essencial

Este é um artigo publicado em acesso aberto (Open Access) sob a licença Creative Commons Attribution, que permite uso, distribuição e reprodução em qualquer meio, sem restrições desde que o trabalho original seja corretamente citado. 
para ampliar compreensões nesse campo do conhecimento científico, tornando-se relevante para o campo do conhecimento do desenvolvimento de carreiras e do empreendedorismo.

Palavras-chave: Desenvolvimento de Carreira. Carreira Empreendedora. Artes Marciais.

\section{ABSTRACT}

Purpose: Investigate the career development of the honorable masters of the oriental martial arts.

Method / approach: The study is qualitative, considering the stages and cycles of the entrepreneurial career. It had as a universe 6 honorable masters of oriental martial arts. Semistructured interviews were used, carried out between November 2014 and September 2015, with a set of techniques inherent to content analysis, following the steps: (i) pre-analysis, (ii) exploration of the material and (iii) treatment results, inference, and interpretation.

Main findings: The subjects' careers resulted in a singular, multichannel, and multicyclic form, in a model of coexistence of the master's career and the entrepreneurial career. In mastery the individual remains in growth throughout his life, with no exit or retirement from the organization. In the entrepreneurial bias, the ventures are added to add value and equity.

Methodological / social / managerial contributions: The study contributes to the field of knowledge of the entrepreneurial career of honorable martial arts masters. It is hoped that this step will add to the scope of research and awaken the opportunity in a new vein on the part of institutions, researchers, and public entities, for the possibilities that this cultural branch can offer, both in philosophical and economic aspects.

Originality / relevance: Honorable martial arts masters, as entrepreneurs, tend to lead careers and lives in line with entrepreneurship and mastery, and this is essential to broaden understandings in this field of knowledge, becoming relevant to the field of scientific knowledge of career development and entrepreneurship.

Keywords: Career Development. Entrepreneurial Career. Martial Arts.

\section{INTRODUÇÃO}

O fenômeno artístico marcial compõe uma inovadora modalidade de carreira (Parizotto, Silva, Junior, \& Starepravo, 2017; Wilson \& Liu, 2012), podendo ser compreendido quando honoráveis mestres, pessoas legitimadas como eméritos mestres, sobretudo pelos praticantes dessas artes, emergem e reúnem aspectos que são comuns à cultura inerente a esse fenômeno e que, consequentemente, encontra-se relacionado ao contexto do empreendedorismo (Cruz, Falcão, \& Petri, 2018; Hyams, 1979).

Ao levar em conta as características de desbravo, criatividade e inovação, um dos tipos de carreira correlatas a dos mestres de honra das artes marciais, consoante a literatura, é a carreira empreendedora, dado que essa carreira busca incorporar a capacidade de criação, de inovação, bem como a possibilidade de originar novos valores e serviços (Chanlat, 1995; Jiang, Newman, Presbitero, \& Zheng, 2019; Oliveira, 2011; Politis, 2005). Ademais, o honorável mestre de artes marciais personifica uma linhagem de concessão para transmitir a honra desses caminhos e de suas técnicas, mas também para estabelecer os seus negócios (Fett \& Fett, 2009; Musashi, 2010; Ueshiba, 1991).

Diante dessas abordagens, este estudo, amparado em delimitações teóricas e epistemológicas, refere-se à carreira dos honoráveis mestres das artes marciais orientais. Para 
tanto, formulou-se a seguinte pergunta para nortear o desenvolvimento desta pesquisa: como se desenvolve a carreira dos honoráveis mestres das artes marciais orientais? Com o intuito de responder à questão de pesquisa, tem-se como objetivo, portanto, investigar o desenvolvimento da carreira dos honoráveis mestres das artes marciais orientais. A análise visa encontrar respostas acerca de carreiras empreendedoras na economia criativa - perfis de carreiras cujas substâncias de significados possam conferir benesses que alcancem também outras carreiras e outros campos do conhecimento.

Esta pesquisa foi desenvolvida na forma de estudo qualitativo, especialmente em virtude do fenômeno investigado na perspectiva dos honoráveis mestres orientais. Para a realização dessa proposta, foram realizadas entrevistas em profundidade com seis honoráveis mestres de artes marciais orientais - com o intuito de investigar o desenvolvimento de suas carreiras empreendedoras. Essa investigação teve como base as fases da carreira empreendedora: caracterização, exploração, crescimento e estabilização - inspiradas nas reflexões teóricas e metodológicas de Harrington e Hall (2007), Degen (2008), Barreto (2013), Hisrich, Peters e Shepherd (2014) e Dornelas, Spinelli, Adams (2014).

A partir disso, o desenvolvimento desta pesquisa se justifica, principalmente, devido à carreira empreendedora dos honoráveis mestres evidenciarem elementos valorizados para a aplicação na vida prática, como princípios relacionadas à unicidade incomum entre as técnicas e a filosofia dessas artes, o negócio que a viabiliza como profissão, entre outros. As relações elementares entre a carreira empreendedora, a maestria em artes marciais e os negócios precisam ser conhecidas, uma vez que podem trazer respostas a problemas enfrentados nas empresas. Essas carreiras têm elementos diferenciados e, por isso, contribuem com as organizações e seus problemas de rotatividade, de falta de permanência e baixo compromisso dos funcionários, de necessidade de paixão e sentido pelo trabalho.

Com base nas reflexões abordadas, cabe mencionar que os honoráveis mestres de artes marciais, enquanto empreendedores, tendem a conduzir carreiras e vidas em consonância com empreendimentos e mestria, sendo essencial para ampliar compreensões nesse campo do conhecimento científico. Nessa perspectiva, o estudo traz à tona mais conhecimentos sobre o desenvolvimento dessas carreiras por meio de ciclos e fases nas suas vidas no desenvolvimento de seus empreendimentos.

Além desta seção introdutória, este estudo segmenta-se em mais quatro seções, sendo a próxima abordando a carreira empreendedora dos honoráveis mestres. Na terceira seção, evidenciam-se os procedimentos metodológicos para a obtenção dos dados. Em seguida, na quarta seção, realiza-se a análise e discussão dos resultados obtidos com o desenvolvimento do estudo. Na quinta seção, considerações finais, apontam-se as contribuições da pesquisa, considerando também reflexões para futuros estudos sobre o tema.

\section{CARREIRA EMPREENDEDORA DOS HONORÁVEIS MESTRES}

As abordagens contemporâneas de carreira, culminadas nos anos 1990, levando-se em conta as ideias de Arthur, Hall e Lawrence (1989) e Bridges (1995), que detêm uma perspectiva de experiências profissionais, no modo como as pessoas interagem com as organizações, sociedade e pessoas, têm entre seus elementos essenciais a responsabilidade e dominância do próprio indivíduo, ao que antes eram devidas às organizações (Balassiano \& Costa, 2006; Martins, 2001; Law, Meijers, \& Wijers, 2002). Diversos autores destacaram que as mudanças sociais e no mundo do trabalho resultaram na carreira em sua versão contemporânea. Esses cientistas - entre eles Arthur, Arthur, Hall e Lawrence (1989), Chanlat (1995), Hall (2002), Greenhaus, Callanan e Godshalk (2010), Chudzikowski (2012) e İspir, Elibol e Sönmez (2019) - 
produziram os conceitos pertinentes à nova carreira sob o predomínio da descontinuidade, da horizontalidade, assim como da instabilidade.

Levando-se em conta a perspectiva de Chanlat (1995), a carreira empreendedora é considerada essencial para a criatividade e inovação, uma vez que é vertente das abordagens na nova sociedade, sendo capaz de possibilitar a criação de novos valores, produtos e serviços. Indivíduos relacionados à inclinação profissional empreendedora perseguem a criação do novo, de novos empreendimentos, mais que isso, essas pessoas perseguem esse comportamento ao longo de suas carreiras (Jiang, Newman, Le, Presbitero, \& Zheng, 2019; Meoli, Fini, Sobrero, \& Wiklund, 2020; Sala, \& Trevisan, 2009; Schein, 1996).

A carreira desses tempos pode ser compreendida em um processo cíclico, com a presença de diferentes estágios (ou etapas) evolutivos, caracterizados por singularidades como temas, tarefas e escolhas próprias (Evans, 1996; Greenhaus, Callanan, \& Godshalk, 2010; Hall, 2002; Harrington \& Hall, 2007). Alguns estudos começaram a relacionar as carreiras a ciclos da vida adulta, entre eles, Hall (2002), que propõe o "Modelo integrado de vida e estágios" composto de cinco etapas: a) Exploração, que é uma fase inicial (até os 25 anos de idade); b) Desenvolvimento, caracterizado por aprendizado e treinamento (25 aos 45 anos de idade); c) Manutenção, que resultaria em estagnação, manutenção ou continuaria um crescimento (45 aos 65 anos de idade); d) Declínio, com aposentadoria e saída (após os 65 anos de idade).

Diante da perspectiva de Hall (2002), por meio do Modelo Integrado de Desenvolvimento de Carreira, é pertinente defini-lo por sua abordagem processual da carreira. Nesta abordagem, ocorrem quatro ciclos ou estágios, sendo as fases: inicial, de crescimento, estagnação e declínio. As razões mais frequentes que levam o indivíduo à fase inicial na carreira empreendedora são os sensos de independência e a necessidade de realização, que estão ligados ao controle sobre a própria vida e sobre o ambiente. 0 empreendedor sente necessidade de sucesso e vitória; para isso, há que suprir a força e a energia para sair da inércia, crescer e manter o crescimento (Degen, 2008; Hisrich, Peters, \& Shepherd, 2014). Outra característica nata ao empreendedor, presente desde a fase inicial, é a aceitação do risco. Aceitar riscos e superá-los reflete na definição de empreender (Degen, 2008; Hisrich, Peters, \& Shepherd, 2014; Meoli, Fini, Sobrero, \& Wiklund, 2020; Twum, Kwakwa, Ofori, \& Nkukpornu, 2021).

Após a fase inicial da carreira empreendedora, segue-se um período de crescimento do empreendimento, elevando o número de processos e atividades exigidos (Hall, 2002; Dolabela, 2012; Zhao, O'Connor, Wu, \& Lumpkin, 2021). O artista empreendedor encontra um conflito entre a dedicação à atividade artística e às atividades demandadas do negócio (Dolabela, 2012; Silva, Paiva, \& Lima, 2019; Ýudice, 2004). Contudo, a criação de valor acelera à medida que a atividade de gosto encontra concórdia e soma forças com as atividades negociais (Limeira 2008). Em sequência à fase de crescimento, ocorreria a fase de saída e aposentadoria (Hall, 2002), que neste estudo é denominado de estabilização. Nesta fase é admitido o reinício para uma carreira tardia, alguns indivíduos desenvolvem a carreira tardia, mesmo depois se afastando e aposentando (Greenhaus, Callanan, \& Godshalk, 2010).

Outra abordagem no campo do conhecimento das carreiras, é a de Harrington e Hall (2007), denominada de "Modelo baseado em ciclos de aprendizagem". Eles entendem que as carreiras modernas são formadas por uma sucessão de pequenos estágios (com curtos ciclos de aprendizagem) de exploração, treinamento, estabelecimento, domínio e saída; nos quais as atividades profissionais do indivíduo são desenvolvidas em várias áreas de produtos, tecnologias, funções, organizações e outros ambientes de trabalho, inclusive alguns estágios 
e atividades podem ocorrer simultaneamente. Os empreendedores utilizam de uma força de ruptura com o antigo rumo a criação do novo (Hall, Yip, \& Doiron, 2018; Hisrich, Peters, \& Shepherd, 2014).

Diante do que foi abordado, é pertinente evidenciar que a carreira empreendedora parece superar o momento estanque do fim da vida. Percebe-se, portanto, que o indivíduo busca estar nela até o final da existência material, mas arvora-se em deixar resíduos de sua arte e atuação para que outros o sucedam. Nesse contexto, a carreira empreendedora parece devolver a essa nova economia talentos e empreendimentos, tanto na presença do indivíduo como por meio de seu legado.

\section{PROCEDIMENTOS METODOLÓGICOS}

O Universo e os sujeitos da pesquisa são os honoráveis mestres de artes marciais orientais. A cuidadosa seleção dos sujeitos é primordial, dado que a ideia fundamental que alicerça o método qualitativo é a de aprender sobre o problema com os sujeitos e obter informações que extrapolem a visão local e virem ciência (Creswell, 2010). A seleção dos sujeitos ocorreu da seguinte forma, selecionou-se as artes marciais de maior relevância, excluindo-se as que guardavam divergência cultural. Depois, por um senso comum presente nos praticantes e por serem consideradas as mais populares e acessíveis, restaram aceitas 7 artes de cunho oriental.

Os sujeitos foram escolhidos se utilizando do cruzamento de diversas referências, e ainda são os considerados pela sociedade como os portadores de honra, caminho e técnica, os honoráveis mestres de cada uma dessas artes. É pertinente mencionar que foram solicitadas ao meio especializado, aos praticantes, às federações e aos outros mestres, um único indivíduo por categoria de cada arte marcial investigada.

Encontraram-se 11 artes marciais de maior relevância no estado do Ceará. Entre essas 11, foram excluídas Capoeira, Boxe e Kickboxing por não terem origem oriental e guardarem substanciais diferenças culturais. Excluiu-se, também, o Krav maga, arte israelita do Oriente Médio, pelas mesmas razões. O mestre do Taekwondo, em viagem, não pôde participar deste estudo. O primeiro contato foi com o mestre Jiu e Mestre Jud, em seguida, utilizou-se da técnica "snowball", bola de neve, em que esses mestres foram indicando outros e assim sucessivamente. A partir disso, foram selecionados os mestres das artes denominados na forma seguinte: (a) Judô - "Jud"; (b) Jiu-Jítsu - "Jiu"; (c) Karatê - "Kar"; (d) Muay Thay - "Mua"; (e) Kung Fu Wushu - "Kun"; (f) Aikido - "Aik".

Utilizou-se como estratégia de coleta as entrevistas semiestruturas, permitindo observar o comportamento e o campo, logrando enriquecimento para o estudo (Creswell, 2010). Obedeceu-se à entrevista prévia para testes, que visou refinar a linguagem ao meio e realidade dos sujeitos e garantir maior aderência à investigação. Todos os honoráveis mestres foram entrevistados presencialmente pelos pesquisadores, nas dependências dos seus locais de trabalho. $O$ roteiro de entrevista consta de 15 questões principais, afora as de controle, obtendo-se um total de 9 horas e 48 minutos de gravações, com média de 1 hora e 35 minutos por cada entrevista realizada pelos pesquisadores. Essas entrevistas em profundidade foram realizadas entre 03 de novembro de 2014 e 13 de setembro de 2015.

A análise dos dados seguiu o protocolo de Bardin (2011), constituindo-se de algumas etapas para a consecução da análise de conteúdo, organizadas em três fases: 1) pré-análise, 2) exploração do material e 3) tratamento dos resultados, inferência e interpretação. 0 protocolo de pesquisa foi elaborado em quatro blocos: (i) Bloco 1 - Caracterização dos Sujeitos; (ii) Bloco 2 - Fase de Exploração; (iii) Bloco 3 - Fase de Crescimento; e (iv) Bloco 4 - 
Fase de Estabilização. Diante disso, a Tabela 1 apresenta a estruturação do roteiro adotado para as entrevistas realizadas com os honoráveis mestres, com base em alguns autores, como Harrington e Hall (2007), Degen (2008), Barreto (2013), Hisrich, Peters e Shepherd (2014) e Dornelas, Spinelli, Adams (2014).

Tabela 1

Categorias de análise, unidades de contexto e autores

\begin{tabular}{|c|c|}
\hline CATEGORIAS DE ANÁLISE & UNIDADES DE CONTEXTO \\
\hline \multirow{6}{*}{ 1. Caracterização } & Presença da inovação e da criatividade. \\
\hline & Presença de talentos e habilidades especiais propícias. \\
\hline & $\begin{array}{l}\text { Criação de riqueza e propriedade intelectual ligada à arte e à cultura. } \\
\text { Produção de bens e serviços criativoscujo valor tem caráter simbólico. }\end{array}$ \\
\hline & $\begin{array}{l}\text { Alto grau de compromisso pessoal e realização de múltiplos papéis, com } \\
\text { carreira e negócio interligados. }\end{array}$ \\
\hline & $\begin{array}{l}\text { Potencial para gerar ocupação e renda, apesar debaixos níveis de } \\
\text { estruturação, previsibilidade e suporte. }\end{array}$ \\
\hline & $\begin{array}{l}\text { Coexistência de aspectos simbólicos da atividade degosto e aspectos } \\
\text { econômico-negociais. }\end{array}$ \\
\hline \multirow{4}{*}{ 2. Exploração } & Ocorrência de sentimentos de independência e necessidade de realização. \\
\hline & Aceitação do risco. \\
\hline & Ingresso sob o regime do empreendedorismo por oportunidade. \\
\hline & Investimento de recursos emocionais e econômicos. \\
\hline \multirow{3}{*}{ 3. Crescimento } & $\begin{array}{l}\text { Paradoxo do conflito entre a subjetividade do artista ea necessidade de } \\
\text { monetizar a arte, até que ocorra relativa conciliação entre arte e negócio. }\end{array}$ \\
\hline & $\begin{array}{l}\text { Agregação de valores econômicos e simbólicosatravés da criatividade e } \\
\text { inovação. }\end{array}$ \\
\hline & $\begin{array}{l}\text { Expansão da cadeia de valor, dos bens e serviços edos resultados. } \\
\text { Materialização do reconhecimento social. }\end{array}$ \\
\hline \multirow{3}{*}{ 4. Estabilização } & $\begin{array}{l}\text { Busca de permanecer em atividade, em detrimento dodeclínio, da estagnação } \\
\text { ou da inatividade laboral. }\end{array}$ \\
\hline & $\begin{array}{l}\text { Maturidade para procura de continuidade/sucessores para o legado e } \\
\text { patrimônio. }\end{array}$ \\
\hline & $\begin{array}{l}\text { Presença de um gatilho para novo início. Começo denovo negócio, produto } \\
\text { ou serviço, nova forma de conceituar a carreira. }\end{array}$ \\
\hline
\end{tabular}

Em vista disso, a partir da coleta e análise dos dados, apresentam-se os resultados encontrados nas entrevistas realizadas com os honoráveis mestres de artes orientais, que foram fundamentais e mostraram importantes resultados para o campo do conhecimento científico das carreiras empreendedoras.

\section{ANÁLISE E DISCUSSÃO DOS RESULTADOS}

Mostra-se, a partir dos resultados encontrados, a carreira empreendedora dos honoráveis mestres de artes marciais, tomando-se como base as suas respectivas fases: caracterização, exploração, crescimento e estabilização.

\subsection{CARACTERIZAÇÃO COMO MESTRES E COMO EMPREENDEDORES}

Os sujeitos da pesquisa têm características que os evidenciam, algumas relacionadas à condição de honoráveis mestres de artes marciais, e outras relacionadas as suas condições empreendedoras, conforme podem ser observadas pela Tabela 2. 
Tabela 2

Caracterização como empreendedor

\begin{tabular}{|c|c|}
\hline \multicolumn{2}{|c|}{ CARACTERIZAÇÃO COMO EMPREENDEDOR } \\
\hline $\begin{array}{c}\text { Mestre } \\
\text { Jud }\end{array}$ & $\begin{array}{l}\text { Tem } 99 \text { anos de idade, } 62 \text { anos de prática no judô, 9o Dan, faixa vermelha, graduado em } \\
\text { educação física, especialista em Educação Física Militar. Primeiro faixa preta de judô do Ceará, } \\
\text { fundou a Federação Cearense de Judô. Montou a academia "Sol Nascente", com sede e mais } 17 \\
\text { núcleos. Detém o título de Shihan (mestre dos mestres), é reconhecido no judô brasileiro. É um } \\
\text { dos idealizadores e implantador do sistema em que se luta por categorias segmentadas pelo } \\
\text { peso dos atletas que é replicado nos combates de artes marciais no mundo. }\end{array}$ \\
\hline $\begin{array}{l}\text { Mestre } \\
\text { Jiu }\end{array}$ & $\begin{array}{l}\text { Com } 52 \text { anos de idade, no 6o dan, desde criança foi preparado por seu pai (faixa vermelha) para } \\
\text { o Jiu-Jítsu e para os negócios, formado em Direito e Educação Física, como empresário detém } \\
\text { várias marcas, times, empresas, promotoras e academias, sediadas no Brasil e fora dele. } \\
\text { Fundador e presidente da Confederação Brasileira de Lutas Profissionais (CBLP) e da Federação } \\
\text { de Jiu-Jítsu e Lutas Profissionais do Ceará (FJJLP-CE), através dessas reconfigurou o Jiu-Jítsu } \\
\text { quanto a padrões visuais e normas de combate, configurando um sistema próprio. Fundador do } \\
\text { "SAZ" Team, inventor do "Promotion Belt". }\end{array}$ \\
\hline $\begin{array}{c}\text { Mestre } \\
\text { Kar }\end{array}$ & $\begin{array}{l}\text { 5o Dan, é precursor dos treinos de campo e coautor pioneiro na literatura do Karatê no Ceará, } \\
\text { "Uma História do Karatê no Estado do Ceará". Aos } 46 \text { anos de idade e } 33 \text { de Karatê é doutor e } \\
\text { professor adjunto da Universidade Estadual do Ceará. Como intraempreendedor idealizou uma } \\
\text { especialização em artes marciais. É coordenador do curso de Educação Física e professor na } \\
\text { disciplina de lutas. É referência acadêmica com publicações, projetos e extensão dedicadas à } \\
\text { arte marcial na Educação Física e que reforçam a posição das artes marciais na sociedade. }\end{array}$ \\
\hline $\begin{array}{c}\text { Mestre } \\
\text { Mua }\end{array}$ & $\begin{array}{l}\text { Implantou o Muay Thay no Ceará. É o único Mestre Cearense e um dos poucos brasileiros. } \\
\text { Fundou e preside a Federação Cearense com confluência do norte e nordeste do Brasil, é } \\
\text { proprietário de academia, coordena } 30 \text { times de lutas, assessora atletas de alta performance } \\
\text { que descobriu, e é proprietário de construtora. Promove eventos da arte marcial com presença } \\
\text { de Grãos mestres e expoentes mundiais. Montou um sistema descentralizado de equipes de } \\
\text { Muay Thay. Teve discípulos campeões brasileiros e mundial na Tailândia. Idealizou projetos } \\
\text { sociais, dentre eles, com meninos de rua, transformando-os em cidadãos e lutadores. }\end{array}$ \\
\hline $\begin{array}{c}\text { Mestre } \\
\text { Kun }\end{array}$ & $\begin{array}{l}\text { Tem } 47 \text { anos de idade e } 36 \text { de kung fu. Foi vice-campeão mundial de Kung Fu. É arbitro nível A } \\
\text { da Confederação Brasileira de Kung Fu Wushu/ International Wuchu Federation/ Comitê } \\
\text { Olímpico Brasileiro. Preside a Federação Cearense de Kung Fu por } 12 \text { anos, proprietário do } \\
\text { Centro de Treinamento Oriental (CTO) e da "MM Fight Team". Palestrante e conferencista, seus } \\
\text { negócios no Kung-Fu são referência. Introduziu o Sanda para o mercado de espetáculos e lutas. } \\
\text { Estabeleceu parceria com entes públicos, oferecendo Tai Shi Shuan (Modalidade do Kung Fu) } \\
\text { nas praças e nas praias. Teve um discípulo Campeão Mundial de Kung Fu na China. }\end{array}$ \\
\hline $\begin{array}{c}\text { Mestre } \\
\text { Aik }\end{array}$ & $\begin{array}{l}\text { Tem } 46 \text { anos de idade e } 25 \text { na arte, sendo faixa preta 5o dan. Proprietário do Linsei dojo, criador } \\
\text { do sistema de treinamento para lideranças Shungyô. É representante oficial no Ceará do oficial } \\
\text { da Fundação Aikikai (Entidade Máxima). Promotor de eventos com expoentes internacionais. } \\
\text { Palestrante e Conferencista sobre proteção e segurança. Idealizador de treinamento de equipes } \\
\text { de segurança de alto nível, familiar e antissequestro. Promotor do uso como auxílio terapêutico } \\
\text { do Aikido, em parceria com psicólogos. }\end{array}$ \\
\hline
\end{tabular}

A análise demonstrou que os honoráveis mestres se caracterizam, de fato, como empreendedores. Seus negócios e vidas sugerem o caminho da criatividade e da inovação, suas carreiras modificaram as artes marciais e os empreendimentos a elas relacionados. Conforme Dornelas, Spinelli e Adams (2014, p.1), "no coração do processo empreendedor existe o fundador: o buscador de oportunidades, o criador e iniciador, o líder, resolvedor de problemas e motivador; o estrategista e guardião da missão, do valor e da cultura da empresa".

Além disso, foi evidenciado que os sujeitos passaram por um período de maturação prévia na qual aprenderam como alunos e depois instrutores - até que estivessem em condições de mestria e empreendedorismo na arte marcial em que é considerado honorável mestre (Barreto, 2013; Hall, 2002; Hyams, 1979). 
Os negócios constituídos foram diversos, reunindo times e marcas sob influência dos sujeitos. Constatou-se, então, que os mestres, excluindo mestre Kar, montaram academia própria. Em uma visão mais ampla, o mestre Kar também trilhou pelo caminho da academia, de ensinar, mas por meio do intraempreendedorismo, promovendo mudanças significativas nas academias nas quais estava presente. Essa constatação corrobora com as ideias de Dolabela (2012), Ratti e Westbook (2006), Greenhaus, Callanan e Godshalk (2010) e Gawke, Gorgievski e Bakker (2019).

As carreiras dos sujeitos apontam responsabilidade social, sendo considerados como agentes de mudanças que extrapolaram fronteiras. Isso, portanto, reflete no que esperam as autoridades que conduzem à inovação e empreendedorismo, além que se mostra de acordo com a nova modelagem das carreiras (De Luca \& Rocha-De-Oliveira, 2015; GEM, 2015; Sullivan \& Baruch, 2009). Observa-se, na jornada dos mestres, elevado compromisso às artes e negócios, ao passo que as atuações no mercado geraram emprego e renda. Consoante ao evidenciado por GEM (2015), Miguez (2007), Greenhaus, Callanan e Goldshalk (2010), o empreendedor se caracteriza por um elevado grau de compromisso e esforço, investindo suas forças, seu conteúdo emocional e financeiro, até que se realize o seu ideal.

Ocorreu a presença do viés econômico e do simbólico que são aspectos essenciais da carreira empreendedora quando imersa no campo cultural. A análise sugere que as artes marciais atuam no indivíduo como um todo, acarretando saúde para corpo e mente, e isto resulta em elevação do valor atribuído (Dolabela, 2012; Dornelas, Spinelli, \& Adams, 2014; Severino, 1988). Porém, os mestres tiveram necessidade de sucesso e coesão entre as artes marciais e os negócios. Viu-se ocorrer um conflito que surge de necessidade de dedicação às artes e aos negócios. Cessado o conflito, houve concórdia das duas vertentes e crescimento conjunto (Dornelas, Spinelli, \& Adams, 2014), da união resultou desenvolvimento das carreiras (Greenhaus, Callanan, \& Godshalk, 2000; Harrington \& Hall, 2007).

Os resultados demonstram potencial desses serviços em academias de ginástica, no setor de esportes, em academias especializadas, em escolas e creches, em setores social e de governo, na preparação de equipes de segurança, em eventos de combates e diversão, dentre outros. Esse resultado corrobora com o abordado por Khapova e Arthur (2011) e Hisrich, Peters e Shepherd (2014), os quais reforçam a necessidade de aprofundar o estudo interdisciplinar, sobretudo devido à importância humana e econômica da carreira. Mestre Kar relata a força dessas artes no meio acadêmico, agregando valor ao serviço e aos empregos, conforme elucidou Dornelas (2009).

\subsection{ANÁLISE DE FATORES PERTINENTES À FASE DE EXPLORAÇÃO}

Passou-se, ainda, a analisar os fatores pertinentes à fase de exploração na carreira dos sujeitos da pesquisa. A Tabela 3 expõe as características desta fase de exploração das carreiras dos honoráveis mestres.

Diante disso, a Tabela 3 resume a fase de exploração da carreira dos sujeitos e demonstra que os mestres têm o sentimento de independência, de fazer da forma que se quer, de fundar, mestre Kar, como intraempreendedor, vai realizar este sentimento criando o novo na circunscrição da instituição (Nassif, Andreassi, \& Simões, 2011). 
Tabela 3

Fase de exploração das carreiras dos honoráveis mestres

\begin{tabular}{|c|c|}
\hline \multicolumn{2}{|c|}{ FASE DE EXPLORAÇÃO DAS CARREIRAS DOS HONORÁVEIS MESTRES } \\
\hline $\begin{array}{c}\text { Mestre } \\
\text { Jud }\end{array}$ & $\begin{array}{l}\text { Em 1967, Jud aproveitou o fato de ser o único faixa preta do Ceará em judô e montou sua } \\
\text { academia, inicialmente em uma salinha. Esta etapa caracterizou-se pelo avanço, apesar das } \\
\text { dificuldades, como o desconhecimento da arte do Judô, o preconceito e as necessidades } \\
\text { financeiras que foram enfrentadas com ajuda dos alunos e empréstimos. Almejava e orgulhava- } \\
\text { se do negócio, ao passo que desbravava. }\end{array}$ \\
\hline $\begin{array}{c}\text { Mestre } \\
\text { Jiu }\end{array}$ & $\begin{array}{l}\text { Nasceu em um ambiente de negócios ligados à arte marcial e foi duramente preparado pelo pai } \\
\text { para a sucessão na busca do melhor, do perfeito. Observa-se a necessidade de realização e } \\
\text { sentimentos de independência, a ponto de pretender melhoria a cada dia, de crescer e acumular. } \\
\text { Foi preparado desde criança a mais que aceitar, querer desafios para superá-los. Sobre a } \\
\text { liderança do pai, viveu a exploração atenuada e dispersa ao longo dos anos. }\end{array}$ \\
\hline $\begin{array}{c}\text { Mestre } \\
\text { Kar }\end{array}$ & $\begin{array}{l}\text { Desde jovem gostava de artes marciais e queria ser professor. Escolheu cursar Educação Física } \\
\text { porque viu a oportunidade de materializar o sonho de ensinar Karatê. Teve de transpor muitos } \\
\text { obstáculos até ingressar na UECE como intraempreendedor. Nos anos de exploração na } \\
\text { "academia" lutou pela mudança do modelo da disciplina de lutas do curso de Educação Física. } \\
\text { Seguiu e formatou a especialização pioneira de "Artes Marciais, Esportes de Combate e Lutas". }\end{array}$ \\
\hline $\begin{array}{c}\text { Mestre } \\
\text { Mua }\end{array}$ & $\begin{array}{l}\text { Iniciou o Muay Thay em uma época de preconceito por isso a passagem à empreendedor teve } \\
\text { longa duração. Havia um sentimento interno de desbravar, de conduzir o esporte à sua maneira, } \\
\text { para isso enfrentou as adversidades de tornar grande o esporte. Nesse sentimento fundou a } \\
\text { Federação, montou a academia, os times e os projetos sociais. Por ser o Muay Thay um esporte } \\
\text { "marginalizado", enfrentou falta de apoio, de patrocínio e de atletas, mas viu nos projetos sociais } \\
\text { um meio de encontrar aprendizes, ao tempo que os confere uma vida melhor com o esporte. }\end{array}$ \\
\hline $\begin{array}{c}\text { Mestre } \\
\text { Kun }\end{array}$ & $\begin{array}{l}\text { Oriundo do interior do Estado, sua jornada foi de bastante perseverança e superação. Houve } \\
\text { longa maturação até o negócio próprio. Montou a academia como um lugar onde pudesse } \\
\text { realizar de seu jeito, dar aula na hora que quisesse e "ganhar dinheiro". Como no Kung fu são } \\
\text { raras as academias bem estruturadas, agregou o Sanda, o Judô, o Jiu-Jítsu e a musculação, disso } \\
\text { fez vantagem. Enfrentou riscos, pediu empréstimos, economizou com as despesas e suplantou } \\
\text { as dificuldades. Treina também equipes governamentais de segurança pública. }\end{array}$ \\
\hline $\begin{array}{c}\text { Mestre } \\
\text { Aik }\end{array}$ & $\begin{array}{l}\text { Iniciou a prática do Aikido visando autodefesa. Percorreu muitos países para se graduar na arte } \\
\text { marcial com mestres renomados. Era professor universitário quando decidiu por montar seu } \\
\text { primeiro dojo. Deixou a Universidade para ser um profissional de Aikido. Teve de enfrentar } \\
\text { diversos obstáculos para montar a academia, como os financeiros e a concorrência de outras } \\
\text { artes. Por ser uma arte marcial com fama elitista o estudo e a montagem da atual academia } \\
\text { foram caros. }\end{array}$ \\
\hline
\end{tabular}

Nesta fase ocorre a necessidade de realização nas carreiras estudadas. Jud iniciou uma arte nova e desconhecida e ainda montou uma academia em tempo que eram raras. Jiu sente essa necessidade como uma obrigação, como se determinado a realizar melhor que seu Pai. Kar encontrou um meio de ultrapassar os contornos da sala de aula, inovando, inclusive, nos projetos de extensão. Mua, portanto, agregou realização social como exigência pessoal, ao tempo que desenvolvia o empreendimento. Kun vem realizando desde jovem, dia após dia, até que tivesse condição de erigir a academia. Aik tem sentimento de realização marcado pela qualidade, realização ordenada. Isso corrobora com o que afirmaram Degen (2008) e Hisrich, Peters e Shepherd (2014), uma vez que o empreendedor, constantemente, tem necessidade de realização, de ser reconhecido, de estabelecer metas e, assim, cumpri-las com o esforço próprio.

Os sujeitos aceitam o risco inerente ao empreendedorismo, quase como uma extensão do que aprenderam na arte marcial, que pressupõe superação. Consoante a perspectiva de Hisrich, Peters e Shepherd (2014), os empreendedores assumem todos os tipos de riscos para realizar, sejam financeiros, sociais ou psicológicos. De acordo com as ideias de Degen (2008), 
o empreendedor, por definição, tem de assumir riscos constantes e o seu sucesso está na capacidade de lidar com eles.

\subsection{ANÁLISE DE FATORES PERTINENTES À FASE DE CRESCIMENTO}

Em relação à fase de crescimento das carreiras, mostra-se a Tabela 4 com a fase de crescimento da carreira dos honoráveis mestres de artes marciais.

Tabela 4

Fase de crescimento das carreiras dos honoráveis mestres FASE DE CRESCIMENTO DAS CARREIRAS DOS HONORÁVEIS MESTRES

\begin{tabular}{|c|c|}
\hline $\begin{array}{c}\text { Mestre } \\
\text { Jud }\end{array}$ & $\begin{array}{l}\text { A Academia "Sol Nascente" cresceu rapidamente. O negócio tornou-se valioso, assim como seu } \\
\text { proprietário destacou-se no meio especializado. Conservou a prática e o ensino do Judô, pois } \\
\text { eram as atividades que mais gostava e delegou as tarefas administrativas à família. Enfrentou } \\
\text { conflito com a delegação das atividades administrativas, teve de vencer o apego, mas o modelo } \\
\text { escolhido deu certo e acabou por favorecer o crescimento de seu nome e da academia. }\end{array}$ \\
\hline $\begin{array}{c}\text { Mestre } \\
\text { Jiu }\end{array}$ & $\begin{array}{l}\text { Como herdou academia renomada, ressalta que a dificuldade enfrentada foi intensificar a } \\
\text { expansão. Foi preparado para exercer atividades de mestre marcial e de empreendedor } \\
\text { havendo concórdia das atividades. Sobrecarrega a vida pessoal, familiar, que deixa em segundo } \\
\text { plano. Teve de concentrar atuação nos negócios e eventos maiores e na negociação. Para isso, } \\
\text { criou departamentos e diretores, mas mantém as decisões em suas mãos, ou da família. }\end{array}$ \\
\hline $\begin{array}{c}\text { Mestre } \\
\text { Kar }\end{array}$ & $\begin{array}{l}\text { Antes de entrar por concurso na universidade, houve um momento de grande conflito, quando } \\
\text { era atleta de alta performance e já reconhecido no Karatê. Ressalta, houvera decidido parar de } \\
\text { competir, nunca de treinar. Na carreira acadêmica, encontrou meio de permanecer mestre de } \\
\text { Karate e contribuir como empreendedor corporativo, agregou valor com publicações, } \\
\text { desenvolvimento de cursos, programas, parcerias universitárias e orientações. }\end{array}$ \\
\hline $\begin{array}{l}\text { Mestre } \\
\text { Mua }\end{array}$ & $\begin{array}{l}\text { O Muay Thay está em crescimento, assim como a carreira de mestre Mua. O conflito entre as } \\
\text { tarefas da prática, do ensino, da descoberta de talentos e da cartolagem da federação fizeram } \\
\text { com que inovasse e formasse um sistema descentralizado, com cerca de } 30 \text { equipes, cada uma } \\
\text { tendo um de seus discípulos à frente. Mas o mestre sofre porque, mesmo delegando funções, } \\
\text { não consegue deixar tudo nas mãos dos aprendizes, e todos querem tê-lo como mestre e chefe. }\end{array}$ \\
\hline $\begin{array}{c}\text { Mestre } \\
\text { Kun }\end{array}$ & $\begin{array}{l}\text { Com o crescimento e a academia, se multiplicaram os alunos, os seminários, os trabalhos, mas } \\
\text { obteve ganhos como não gastar tempo de deslocamento para dar aulas. O quesito } \\
\text { administrativo passou à esposa e centrou-se nas aulas, treinos, e escolhas relativas à arte } \\
\text { marcial. Racionalizou viagens, presença na federação, atividades sociais, e competições que são } \\
\text { planejadas. Seu próprio treinamento ocorre quando treina os alunos ou equipes de segurança } \\
\text { que instrui. Porém, acredita que está acertando tudo para realizar o sonho de mestre com } \\
\text { negócio próprio. }\end{array}$ \\
\hline $\begin{array}{c}\text { Mestre } \\
\text { Aik }\end{array}$ & $\begin{array}{l}\text { A carreira empreendedora do mestre encontra-se em início de crescimento. Muito devotado à } \\
\text { perfeição técnica, acredita que sua arte não pode ser aplicada em larga escala, mas o } \\
\text { crescimento já o impede de ministrar todas as aulas no dojo e acompanhar todos os alunos. Para } \\
\text { ganhar tempo, divide a administração com um grupo de alunos. Também atua no curso de } \\
\text { lideranças e no treinamento de equipes de segurança familiar. Pretende agregar Yoga, } \\
\text { massagens orientais, atividades para a terceira idade, enfim, utilizar o espaço com atividades } \\
\text { correlatas ao Aikido. }\end{array}$ \\
\hline
\end{tabular}

É pertinente evidenciar que nesta fase ocorre crescimento do empreendimento e, consequentemente, da atividade empreendedora, resultando inicialmente em um conflito de escolha entre dedicar-se mais à atividade de gosto ou aos negócios que se ampliam (Dornelas, Spinelli, \& Adams, 2014; Ýudice, 2004).

Ao menos três dos mestres, Jud, Kun e Aik, nas escolhas de prioridades, dispuseram em segundo plano parte dos processos e a administração do empreendimento que delegaram a terceiros. No entanto, centraram-se na prática da arte marcial e no ensino técnico e simbólico. Em meio à etapa de crescimento, Mua descentralizou as equipes e manteve o 
controle. Mestre Kar, em outra vertente da carreira, também tem que administrar suas prioridades para bem realizar.

Um crescimento mais acentuado ocorreu com a atividade de mestre Jiu, que, em seu relato, atribui peso para essa expansão à preparação desde a infância para a arte marcial e para os negócios do clã. Sendo assim, um empreendimento tende a crescer na medida em que a atividade fica associada à paixão, sendo alinhada aos aspectos negociais.

\subsection{ANÁLISE DE FATORES REFERENTES À FASE DE ESTABILIZAÇÃO}

Na carreira empreendedora, acredita-se que ocorram variações na última fase em relação a um padrão não empreendedor. A Tabela 5 demonstra a percepção dos entrevistados quanto à fase de estabilização de suas carreiras.

Tabela 5

Fase de estabilização da carreira dos honoráveis mestres

\begin{tabular}{|c|c|}
\hline \multicolumn{2}{|c|}{ FASE DE ESTABILIZAÇÃO DA CARREIRA DOS HONORÁVEIS MESTRES } \\
\hline $\begin{array}{l}\text { Mestre } \\
\text { "Jud" }\end{array}$ & $\begin{array}{l}\text { Aos } 98 \text { anos permanece ativo. Até os } 95 \text { era o atleta mais idoso em luta. Resoluto, afirma que } \\
\text { com o Judô e com as atividades a ele relacionadas não vai parar nunca. Explica que ainda fará } \\
\text { muito mais, que não há aposentadoria no Judô, devido às limitações da idade contribuirá com } \\
\text { sua mente e seus ensinamentos. O Shihan tem planos para o futuro, deseja concluir um estudo } \\
\text { que mudará a forma de competir. Jud deseja fortalecer o ingresso de crianças na arte, dentre } \\
\text { outros planos. }\end{array}$ \\
\hline $\begin{array}{l}\text { Mestre } \\
\text { "Jiu" }\end{array}$ & $\begin{array}{l}\text { O pensamento de parar empreendimentos e Jiu-Jítsu não existe. Há inquietação em realizar, em } \\
\text { fazer melhor. Planeja uma fundação com o nome do pai. Serão grandes sedes com galpão, } \\
\text { trabalharão as lutas, a educação religiosa, a questão dentária, dentre outras. Essa se viabilizará } \\
\text { por doações nacionais e internacionais que já estabeleceu os contatos. Pretende fazer } \\
\text { mapeamento das academias e times, fortificar a cultura do contrato, implantar o seguro para os } \\
\text { atletas. Jiu só deseja iniciar outros negócios que se vão agregando a sua rede. }\end{array}$ \\
\hline $\begin{array}{c}\text { Mestre } \\
\text { "Kar" }\end{array}$ & $\begin{array}{l}\text { Há a premissa de nunca estar satisfeito, entende que muito realizou, porém muito ainda tem } \\
\text { para realizar. Para o Karatê nunca se atinge a perfeição e disse ter muito a contribuir. Também } \\
\text { na vida acadêmica não se para nunca, sempre se busca conhecimento. Deseja produzir mais na } \\
\text { academia, até pela condição do conhecimento científico, que se cresce agregando camadas. } \\
\text { Deseja ir além, busca a implantação de novos projetos que abrirão novas vertentes. }\end{array}$ \\
\hline $\begin{array}{l}\text { Mestre } \\
\text { "Mua" }\end{array}$ & $\begin{array}{l}\text { Tem pensamento voltado para o crescimento, para avançar na contribuição ao Muay Thay. O } \\
\text { Muay Thay exclui a interrupção, não se sai e nem se para. Uma realização pessoal foi o título } \\
\text { mundial de um aluno, mas se diz longe de estar satisfeito. Pretende agregar aos times, o Muay } \\
\text { Thay Boran, o trazendo principalmente ao Nordeste. Iniciou um projeto contra o "bullying" } \\
\text { escolar e outro com auxílio a pessoas especiais. Pretende alavancar o desenvolvimento e } \\
\text { empresariado de atletas, com a caça de talentos. }\end{array}$ \\
\hline $\begin{array}{l}\text { Mestre } \\
\text { "Kun" }\end{array}$ & $\begin{array}{l}\text { Sente-se como um grão com muita coisa pela frente. Diz ter sonhos muito maiores nos } \\
\text { empreendimentos e na arte marcial. Mesmo com idade avançada entende que da luta "nunca } \\
\text { vai se aposentar". Quando idoso, pretende ter uma turma para "brincar e reencontrar velhos } \\
\text { amigos". Ressoa a promessa que fez a seu mestre "Nereu Graballos", fazer o Kung Fu saber quem } \\
\text { é Kun. Projeta a ampliação da academia, deseja caçar e ser empresário de talentos. Supõe tornar } \\
\text { o Kung Fu Sanda uma modalidade conhecida de "MMA", entre outros projetos. }\end{array}$ \\
\hline $\begin{array}{l}\text { Mestre } \\
\text { "Aik" }\end{array}$ & $\begin{array}{l}\text { Aik se acredita com caminho um longo a trilhar. Disse que estar realizado, no sentido de coisa } \\
\text { acabada, nunca estará, porque nunca se está pronto, mas se entende preparado para as } \\
\text { situações. Porém, acredita-se realizado no sentido de feliz, pois estará feliz enquanto aluno tiver } \\
\text { e enquanto puder praticar a paixão pelo Aikido. Deixar o Aikido e os empreendimentos relativos } \\
\text { a ele seria não estar preparado e nem feliz. Embora não veja o emprego anacrônico do Aikido } \\
\text { deseja ampliar o uso do dojô ofertando modalidades artísticas e filosóficas correlatas ao Aikido, } \\
\text { como yoga, pilates, ikebana, bonsai e arteterapia. Deseja focar e desenvolver atividades para o } \\
\text { público de terceira idade. De tudo exige profissionais e ensino de qualidade. }\end{array}$ \\
\hline
\end{tabular}


A partir da Tabela 5, constata-se a posição dos honoráveis mestres de artes marciais a respeito de se sentirem realizados e se pensavam em aposentadoria da arte ou dos negócios quando fosse o tempo em suas vidas. Os resultados convergem no argumento de que não há aposentadoria nem saída nessas carreiras. Os resultados apontaram para um tipo de carreira com comportamentos inusitados como mestres e como empreendedores.

A carreira de Shihan (mestre dos mestres) Jud, observada sob o aspecto cronológico, extrapolou a idade de aposentadoria, ou de ocorrer declínio ou estagnação (Hall, 2002; Greenhaus, Callanan, \& Godshalk, 2010). Nessa carreira, houve substituição de atividades correlatas aos conceitos físicos da arte, como a luta e as aulas físicas, por atividades de conteúdos mentais e espirituais da carreira de um mestre. Ele reflete nos empreendimentos, onde passa a atuar como uma espécie de embaixador de honra, ou seja, de honorável mestre. Isso se justifica pelo natural declínio físico, permanecendo a ascendência de experiências de vida e do respeito por parte dos discípulos.

No "Modelo integrado de vida e estágios de carreira" de Hall (2002), uma abordagem relacionada à idade dos entrevistados, Jiu, Kar, Mua, Kun e Aik estariam em uma fase de manutenção da carreira de mestres. Nesta etapa, além de um período maior de estagnação, os indivíduos poderiam iniciar o declínio, ou continuar o crescimento até os 65 anos de idade, quando haveria declínio. Embora permita o crescimento continuado, essa teoria contradiz o desejo dos mestres que pretendem manter o crescimento sem possibilidade de declínio.

Na ótica empreendedora, o modelo que pode explicar em parte o fenômeno é a "Carreira baseada em ciclos de aprendizagem" de Harrington e Hall (2007), no qual a carreira se vincula ao tempo de aprendizagem e não à idade do indivíduo. Os resultados demonstram a existência de um gatilho produtor do novo, que faz nascer um novo empreendimento, produto ou serviço. Isso ocorre mesmo os sujeitos estando em fases diversas e em idades diferentes. O resultado corrobora com o relatório GEM (2015), que define a essência do empreendedorismo como a tentativa de novos negócios, a criação de novos produtos e empresas por um indivíduo, ou até mesmo um grupo de indivíduos.

De modo geral, o estudo demonstra que as carreiras dos honoráveis mestres de artes marciais, no que diz respeito à maestria, permanecem em crescimento, e no que concerne aos empreendimentos, não há uma saída necessária, mas podem existir diversos inícios baseados em se cumprirem tempos de aprendizagens. Nesse sentido, a carreira dos honoráveis mestres de artes marciais é multicanal e multicíclica. Assim, a pesquisa corrobora com alguns estudos que propõem o avanço na descoberta de novas configurações de carreiras e relações entre estrutura das organizações, indivíduos, disciplinas e aspectos sociais e individuais (De Luca \& Rocha-De-Oliveira, 2015; Inkson, Gunz, Ganesh, \& Roper, 2012; Kaphova \& Arthur, 2011).

\section{CONSIDERAÇÕES FINAIS}

Este estudo objetivou investigar o desenvolvimento da carreira dos honoráveis mestres das artes marciais orientais, supondo que o desenvolvimento profissional dos sujeitos se realiza em ciclos e estágios e em uma concepção empreendedora. Nesse sentido, enquanto mestres, suas carreiras obedecem a um aprendizado prévio como alunos e instrutores, sucedido por um período de união à atividade empreendedora e crescimento até que se estabilizam em crescimento contínuo.

Os resultados apontaram, ainda, para um aspecto característico das carreiras dos sujeitos. Essas pareceram ter essencial relacionamento com a transmissão de conhecimento, de legado. Segundo os achados desta pesquisa, os honoráveis mestres, embora não 
intentassem abandonar a carreira de mestres artistas marciais, prepararam discípulos e sucessores, porque sabem que envelhecem e que vão precisar de sucessores. Nesse entendimento, formaram um grupo com características familiares ou mesmo como um clã, em que os caminhos de vida e carreira encontrados foram repassados como um legado.

O estudo destaca os honoráveis mestres de artes marciais como fundadores e inovadores, uma vez que constituem federações, negócios, times e marcas. Um ponto comum entre os mestres é a existência de academia - para que possam repassar elementos de mestria, que estão, muitas vezes, ancorados nos empreendimentos que se desenvolvem ao redor deles.

Observou-se um construto de carreira com conteúdo e canais distintos, que somam forças para o crescimento. Os conteúdos essenciais da carreira empreendedora, como necessidade de realização e aceitação do risco se incorporaram aos sujeitos sendo reforçadas nas artes marciais na forma de busca da perfeição, perseverança e superação dos limites. Os resultados demonstram que a carreira do mestre prospera quando as disciplinas da atividade de gosto, arte marcial, e os aspectos relativos aos negócios encontram equilíbrio e o mestre pode dedicar-se aos dois, permitindo favorecimento mútuo.

Esta pesquisa avançou em identificar uma nova carreira que se constituiu empreendedora e na economia criativa. Emergiu, portanto, uma carreira multicanal e multicíclica, em que há coexistência da atividade de mestre de artes marciais e de atividades empreendedoras, que se desenvolvem em ciclos que se vão somando em empreendimentos - com conteúdo simbólico e cultural que revela distanciamento em alguns aspectos das carreiras estudadas em outros trabalhos. Os mestres ignoram a rotatividade, absenteísmo e a aposentadoria, por exemplo, para Mestre Muay, reconhecido pelo rei da Tailândia, são necessários 30 anos de prática ininterrupta. Mestre Jud, com quase 100 anos, alegou que estava apenas começando. Isto pode ser de grande valia nas organizações caso se ministrem aspectos simbólico similares.

Como contribuição metodológica, procurou-se ampliar compreensões sobre a carreira empreendedora dos honoráveis mestres de artes marciais por meio de entrevistas em profundidade, grupo este que é considerado enorme e coeso de indivíduos. Além disso, buscou-se qualificar exponencialmente para que seu conteúdo representasse as características de uma parcela social representativa.

Em relação às contribuições gerenciais, revelou-se um novo tipo de carreira que se desenvolve Multicanal e Multicíclica, cujos conteúdos simbólicos resultam em não estagnação e não aposentadoria. No perfil econômico, foi possível encontrar carreiras que somam valores paralelos em diversas atividades, formando um grupo de perceptos financeiros, inclusive com legado para a sucessão.

O desenvolvimento desta pesquisa se mostrou relevante, sobretudo por possibilitar trazer um novo olhar para uma carreira pouco explorada na literatura e que pode ser exemplo ou emprestar conceitos e laços a outras carreiras. Em outra análise, incorporar características orientais à carreira ocidental, como o respeito, a concorrência ética, a superação interior, dentre outras características perpassadas por meio das entrevistas que foram realizadas com os honoráveis mestres de artes marciais.

Propõe-se, portanto, o aprofundamento das pesquisas no campo das artes marciais e sua interface administrativa. Pode-se estudar indivíduos, equipes e organizações, nas mesmas artes marciais ou em artes que guardam aspectos culturais diferentes. É relevante aprofundar as pesquisas sobre a relação empreendedorismo, artes marciais e constituição de riqueza, 
investigar a respeito do significado e permanência no trabalho, assim como sobre a longevidade das carreiras.

\section{REFERÊNCIAS}

Arthur, M. B., Hall, D. T., \& Lawrence, B. S. (1989). Generating new directions in career theory: The case for a transdisciplinary approach. Handbook of career theory, 7, 25.

Arthur, M. B., Arthur, M. B., Hall, D. T., \& Lawrence, B. S. (Eds.). (1989). Handbook of career theory. Cambridge University Press.

Balassiano, M., \& Costa, I. S. (2006). Gestão de carreiras: dilemas e perspectivas. São Paulo: Atlas.

Bardin, L. (2011). Análise de conteúdo (4a ed.). Lisboa: Edições, 70, 1977.

Barreto, A. (2013). Elementos para se pensar uma carreira profissional artística e criativa. Revista Cadernos do Ceom, 26(39), 119-132.

Bridges, W. (1995). [Book Review] JobShift, how to prosper in a workplace without jobs. Monthly Review, 47(1), 39-51.

Chanlat, J. F. (1995). Quais carreiras e para qual sociedade? Revista de Administração de Empresas, 35(6), 67-75.

Chudzikowski, K. (2012). Career transitions and career success in the 'new' career era. Journal of Vocational Behavior, 81(2), 298-306.

Creswell, J. W. (2010). Projeto de pesquisa métodos qualitativo, quantitativo e misto. In Projeto de pesquisa métodos qualitativo, quantitativo e misto (3a ed., pp. 296). Porto Alegre: Artmed.

Cruz, E., Falcão, R. P. Q., \& Petri, F. C. (2018). Explorando o empreendedorismo do enclave brasileiro no sul da Flórida. Revista Eletrônica de Estratégia \& Negócios, 11(1), 138-164.

De Luca, G., \& Rocha-de-Oliveira, S. (2015, setembro 13-16). Carreiras com tinta: desenhando uma trajetória profissional no campo da tatuagem. Encontro da ANPAD, Belo Horizonte, MG, Brasil. http://www.anpad.org.br/abrir_pdf.php?e=MjAwODc.

Degen, R. J. (2008). Empreendedorismo: uma filosofia para o desenvolvimento sustentável e a redução da pobreza. Revista de Ciências da Administração, 10(21), 11-30.

Dornelas, J. C. A. (2009). Empreendedorismo corporativo. (3a ed., pp. 250-250). Rio de Janeiro: Elsevier.

Dornelas, J., Spinelli, S., \& Adams, R. J. (2014). Criação de novos negócios: empreendedorismo para o século 21 (2a ed.). São Paulo: Elsevier. 
Dolabela, F. (2012). O segredo de Luísa. São Paulo: Sextante.

Evans, P. (1996). Carreira, sucesso e qualidade de vida. Revista de Administração de empresas, 36, 14-22.

Fett, C. A., \& Fett, W. C. R. (2009). Filosofia, ciência e a formação do profissional de artes marciais. Motriz, 15(1), 173-184.

Gawke, J. C., Gorgievski, M. J., \& Bakker, A. B. (2019). Measuring intrapreneurship at the individual level: Development and validation of the Employee Intrapreneurship Scale (EIS). European Management Journal, 37(6), 806-817.

GEM. (2015). Empreendedorismo no Brasil-relatório executivo 2015. Curitiba: IBQP.

Greenhaus, J. H., Callanan, G. A., \& Godshalk, V. M. (2010). Career management. London: Sage.

Hall, D. T. (2002). Careers in and out of organizations. London: Sage.

Hall, D. T., Yip, J., \& Doiron, K. (2018). Protean careers at work: Self-direction and values orientation in psychological success. Annual Review of Organizational Psychology and Organizational Behavior, 5, 129-156.

Harrington, B., \& Hall, D. T. (2007). Career management \& work-life integration: Using selfassessment to navigate contemporary careers. London: Sage.

Hisrich, R. D., Peters, M. P., \& Shepherd, D. A. (2014). Empreendedorismo-9. New York: The McGraw-Hill Global Education Holding.

Hyams, J. (1979). O zen nas artes marciais. São Paulo: Pensamento.

İspir, Ö., Elibol, E., \& Sönmez, B. (2019). The relationship of personality traits and entrepreneurship tendencies with career adaptability of nursing students. Nurse education today, 79, 41-47.

Inkson, K., Gunz, H., Ganesh, S., \& Roper, J. (2012). Boundaryless careers: Bringing back boundaries. Organization Studies, 33(3), 323-340.

Jiang, Z., Newman, A., Le, H., Presbitero, A., \& Zheng, C. (2019). Career exploration: A review and future research agenda. Journal of Vocational Behavior, 110, 338-356.

Khapova, S. N., \& Arthur, M. B. (2011). Interdisciplinary approaches to contemporary career studies. Human relations, 64(1), 3-17.

Law, B., Meijers, F., \& Wijers, G. (2002). New perspectives on career and identity in the contemporary world. British Journal of Guidance and Counselling, 30(4), 431-449. 
Limeira, T. M. V. (2008, maio 28-30). Empreendedor cultural: perfil e formação profissional. IV Encontro de Estudos Multidisciplinares de Cultura. UFBA Encontro de estudos multidisciplinares em cultura. Salvador, BA, Brasil. http://www.cult.ufba.br/enecult2008/14310.pdf

Marta, F. E. F. (2009). A memória das lutas ou o lugar do "DO": as artes marciais e a construção de um caminho oriental para a cultura corporal na cidade de São Paulo. São Paulo (SP): Pontíficia Universidade Católica. [Tese de Doutorado, Pontifícia Universidade Católica de São Paulo]. Repositórios da Pontifícia Universidade Católica de São Paulo.

https://tede.pucsp.br/bitstream/handle/13145/1/Felipe\%20Eduardo\%20Ferreira\%20Marta. pdf.

Martins, H. T. (2001). Gestão de carreiras na era do conhecimento. Rio de Janeiro: Qualitymark.

Meoli, A., Fini, R., Sobrero, M., \& Wiklund, J. (2020). How entrepreneurial intentions influence entrepreneurial career choices: The moderating influence of social context. Journal of Business Venturing, 35(3), 105982.

Miguez, P. (2007). Economia criativa: uma discussão preliminar. Teorias e políticas da cultura: visões multidisciplinares. Salvador: EDUFBA, 95-114.

Musashi, M. (2010). O livro dos cinco anéis. São Paulo: Clio.

Nassif, V. M. J., Andreassi, T., \& Simões, F. (2011). Competências empreendedoras: há diferenças entre empreendedores e intraempreendedores? RAl Revista de Administração $e$ Inovação, 8(3), 33-54.

Oliveira, L. B. (2011). Carreiras "exóticas": o que administradores podem aprender com as vivências de artistas, atletas e outros profissionais. Revista de Carreiras e Pessoas (ReCaPe), 1(2), 1-28.

Parizotto, P. G. G., Silva, A. F. Z., Junior, C. H., \& Starepravo, F. A. (2017). O processo de institucionalização e regulamentação de artes marciais orientais no Brasil. Caderno de Educação Física e Esporte, 15(1), 53-62.

Politis, D. (2005). The process of entrepreneurial learning: A conceptual framework. Entrepreneurship heory and practice, 29(4), 399-424.

Ratti, O., \& Westbrook, A. (2006). Segredos dos samurais: as artes marciais do Japão feudal. São Paulo: Madras.

Sala, O. T. M., \& Trevisan, L. N. (2009). Competência e carreira profissional: tendências de um objeto de estudo sob as abordagens multidisciplinares. Revista Gestão Organizacional, 2(2), 138-151. 
Schein, E. H. (1996). Career anchors revisited: Implications for career development in the 21st century. Academy of Management Perspectives, 10(4), 80-88.

Severino, R. E. (1988). O espírito das artes marciais. São Paulo: Roque Enrique Severino.

Silva, M. R. R., Paiva, L. E. B., \& Lima, T. C. B. (2019). Entre risos e negócios: uma análise das competências empreendedoras dos humoristas. Revista de Empreendedorismo e Gestão de Pequenas Empresas, 8(2), 292-318.

Sullivan, S. E., \& Baruch, Y. (2009). Advances in career theory and research: A critical review and agenda for future exploration. Journal of Management, 35(6), 1542-1571.

Twum, K. K., Kwakwa, P. A., Ofori, D., \& Nkukpornu, A. (2021). The relationship between individual entrepreneurial orientation, network ties, and entrepreneurial intention of undergraduate students: implications on entrepreneurial education. Entrepreneurship Education, 4(1), 39-66.

Ueshiba, M. (1991). Budô-ensinamentos do fundador do Aikido. São Paulo: Cultrix.

Yin, R. K. (2015). Estudo de Caso-: Planejamento e métodos. Porto Alegre: Bookman editora.

Ýudice, G. (2004). A conveniência da cultura. Usos da cultura na era global. Belo Horizonte: Editora UFMG.

Wilson, J. A., \& Liu, J. (2012). From laconophilia to 'The Sportan': balancing athletic excellence, sponsorship, branding and career prospects. International Journal of Sport Management and Marketing, 11(1-2), 125-142.

Zhao, H., O'Connor, G., Wu, J., \& Lumpkin, G. T. (2021). Age and entrepreneurial career success: A review and a meta-analysis. Journal of Business Venturing, 36(1), 106007. 